further education of health professionals and their clients is essential if we are to improve knowledge, practice \& prevention of FAS worldwide.

Acknowledgements: Thanks to the participating health professionals.

193

\section{THE RNA-BINDING PROTEIN RBM3 IS INVOLVED IN HYPOTHERMIA INDUCED NEUROPROTECTION}

\section{S. Wellmann ${ }^{1}$, A. Zelmer ${ }^{2}$, C. Nitsch ${ }^{3}$,} H.U. Bucher ${ }^{1}$, C. Bührer

${ }^{1}$ Department of Neonatology, University Hospital Zürich, Zürich, ${ }^{2}$ Department of Neonatology,

University Children's Hospital Basel, ${ }^{3}$ Department of Neuroanatomy, University Basel, Basel,

Switzerland, ${ }^{4}$ Department of Neonatology, Charité University Medical Center, Berlin, Germany

Background: Induced hypothermia is the only therapy with proven efficacy to reduce brain damage after perinatal asphyxia. While hypothermia downregulates global protein synthesis and cell metabolism, low temperature induces a small subset of proteins that includes the RNA-binding protein RBM3, which is transcriptionally induced also in response to hypoxia and has recently been implicated in cell survival.

Methods/results: We studied RBM3 expression in thedevelopingmurinebrainbyimmunohistochemistry and found RBM3 widely expressed in neurons of the hippocampus, the subventricular zone, and the cerebellum during the first postnatal days. In adult brains, RBM3 was present only in neuronal precursor and stem cells, characterized by the presence of doublecortin. Hypothermia profoundly promoted RBM3 expression in juvenile as well as in mature neurons, and hypothermia-induced RBM3 expression was associated with protection of primary neurons and neuronal cell lines from forced apoptosis. Blocking RBM3 expression by siRNAs in neuronal cells significantly diminished the neuroprotective effect of hypothermia while vectordriven RBM3 overexpression prevented activation of caspase-3.

Conclusion: Together, the RNA-binding protein RBM3 protects neuronal cells from apoptosis. RBM3 upregulation apparently accounts for a substantial proportion of hypothermia-induced neuroprotection.
194

\section{HYDROCORTISONE VERSUS DEXAMETHASONE TREATMENT FOR BRONCHOPULMONARY DYSPLASIA AND NEUROLOGICAL OUTCOME IN PRETERM INFANTS}

M.M. Hitzert ${ }^{1}$, M.J.N.L. Benders ${ }^{2}$, A.M. Roescher ${ }^{1}$, F. van $\mathrm{Bel}^{2}$, L.S. de Vries ${ }^{2}$, A.F. Bos ${ }^{1}$

${ }^{1}$ Division of Neonatology, Beatrix Children's Hospital, University Medical Center, Groningen,

${ }^{2}$ Department of Neonatology, Wilhelmina Children's Hospital, Utrecht, The Netherlands

Background and aims: At present, hydrocortisone $(\mathrm{HC})$ as well as dexamethasone (DXM) are used to treat preterm infants at risk for bronchopulmonary dysplasia. Our aim was to determine the influence of HC- and DXM-therapy in preterm infants on neurodevelopmental outcome assessed by the quality of general movements (GMs) until three months after term.

Methods: Thirty-six preterm infants were included, 18 infants received $\mathrm{HC}$ (BW range 630-1700 grams, GA range 24.9-31.0 weeks), 18 infants received DXM (BW range 700-1800 grams, GA range 26.0-30.3 weeks) in a mean cumulative equivalent cortisol dose of $113.3 \mathrm{mg} / \mathrm{kg}$ resp. 166.3 $\mathrm{mg} / \mathrm{kg}$. After videotape recording, we analyzed each recording on the quality of GMs as normal or abnormal. Additionally, we performed a Motor Optimality Score (MOS) on details of the GMs (range 5-28).

Results: No difference in GM quality was found between HC- and DXM infants, neither before treatment, nor in the first week after treatment or at term. At 3 months, $\mathrm{HC}$ infants had a higher median MOS than DXM infants (24 vs. 21, $p=0.025$ ). This effect became stronger after correction for equivalent dose of cortisol, BW and GA ( $p=0.005)$. In the DXM group, but not in the HC group, MOS on day 1 of treatment was lower than before treatment (10 vs. $11, p=0.030$ ).

Conclusions: Our study indicates that the quality of GMs is impaired in DXM treated infants, in particular on the first day following treatment. $\mathrm{HC}$ treatment is associated with a better quality of GMs 3 months after term. 